\title{
It Starts With a Journey: Global Learning as Holistic, Interdisciplinary Curricular and Co-Curricular Framework at a Liberal Arts College ${ }^{1}$
}

\author{
Gundolf Graml \\ Agnes Scott College \\ Regine O. Jackson \\ Agnes Scott College
}

This article introduces Agnes Scott College's model for a comprehensive and interdisciplinary approach to global (service) learning and leadership in the liberal arts. We outline strategic perspectives and a specific toolkit for developing holistic global learning frameworks and we detail how this approach integrates local community-campus partnerships, fosters interdisciplinary collaboration between the humanities, social sciences, and STEM disciplines, and foregrounds an intentional and inclusive approach that provides access to global learning experiences for traditionally under-represented groups. The authors share their experiences in the co-construction of programs with full participation and inclusion of diverse and diffuse stakeholders.

Keywords: global learning, pedagogy, diversity, inclusion, general education

\section{INTRODUCTION}

SUMMIT is a faculty-designed and faculty-administered global learning curriculum that strives to offer every student at Agnes Scott College a global education. Guided by a set of college-wide learning goals, faculty from across the disciplines and staff from across campus collaborate to offer a program that combines required general education, elective global learning courses, and co-curricular programming to provide students with the competencies and skills for thriving in a global environment. At the heart of the approach is a required first-year, four-credit, semester-long Global Journeys course, whose 13 to 17 sections include a one-credit, week-long travel segment. The courses balance the various disciplinary-based approaches to global learning with a set of common themes designed to prompt an intentional and selfcritical questioning of the power relations that undergird global learning curricula in Western institutions of higher education.

In what follows, we describe:

- A comprehensive approach to global learning that centers a critical focus on themes of identity/self/culture/other and colonialism/imperialism/diaspora as examples of contact, power, and systems that cross or transcend national borders in our core curriculum;

- The required, first-year interdisciplinary faculty-led study away course that explicitly acknowledges that the U.S. is part of the global dynamics under examination; and 
- Attention to the intersectional effects of students' race, class, gender and sexual identities in all of our programming including co-curriculars, pre-departure orientation and other preparations for study abroad, faculty development, and cultural immersion sites, including our own assessment and research.

We also share sample learning outcomes, course topics, activities, materials, faculty development strategies, and lessons learned for cultivating social justice and intercultural competence through liberal arts general education.

\section{INSTITUTIONAL CONTEXT}

Agnes Scott College is a private, women's college in Decatur, GA about six miles from downtown Atlanta. SUMMIT builds on the College's long track record of providing access to study abroad for students who were historically excluded from those opportunities, while responding to the needs of one of the most diverse student populations in the country. Thirty years ago, Agnes Scott was a very small (less than 600 students), predominantly white institution. The College now enrolls 1,080 students representing 43 U.S. states and territories and 28 countries. Among the students, there is no racial or ethnic majority approximately one-third identify as white, about a third identify as Black or African-American, and a third identify as people of color or historically underrepresented groups. Up to 15 percent of our incoming classes have been international students and the College continues its proactive international enrollment efforts despite the current geopolitical climate. Furthermore, 41 percent of the students are Pell-eligible and 33 percent are first-generation college students (Common Data Set, 2021).

While Agnes Scott embraces its identity and mission as a women's college, the College also welcomes students who were assigned male or female at birth, but who now identify as female, transgender, agender, gender fluid or non-binary. A significant number of students identify as members of the LGBTQI+ community. Our students also belong to various religious groups. Finally, with almost 29 percent of tenureline faculty belonging to historically underrepresented groups, Agnes Scott faculty diversity is on par with, or exceeds, that at most national liberal arts colleges. Issues of diversity and inclusion have been prioritized in faculty and staff development in recent years. And Agnes Scott students have a reputation as progressive, critical thinkers.

Beyond these markers of representational diversity, the College has had a general education requirement intentionally related to racial and cultural diversity for decades. Each student was required to take a social and cultural analysis course in which the central focus was the critical examination of relationships, interactions and outcomes among dominant and marginalized cultures, subcultures or groups. However, in 2015 the College reinvented its approach to general education to better prepare all students to be effective change agents in a global society through the SUMMIT initiative. SUMMIT provides every Agnes Scott student with a curricular and co-curricular experience focused on global learning and leadership development which builds the digital and other competencies necessary for post-graduate success. Initially, every student was supported by a personal "board of advisors." Later we added curricular and co-curricular offerings to center global learning as students complete major requirements. From the beginning of their four years, students learn how to recognize and navigate global structures and challenges that span the globe and impact human experience. Through the implementation of SUMMIT, we have discovered new possibilities and practices for how our distinctive global learning curriculum and social justice pedagogy can elevate the intercultural competency of our students.

The SUMMIT curriculum contributes to conversations globally about race and social justice while examining the operation of power structures in our educational institutions, local communities, as well as our interactions on campus. Our continual innovation of the global learning components of SUMMIT attest to our commitment to addressing the residual impact of hierarchies of human value and a lack of cultural sensitivity in a Eurocentric liberal arts curriculum. We argue that the College's model for global learning disrupts what Mitchell et al. (2012) describe as a "pedagogy of whiteness" (strategies of instruction that consciously or unconsciously reinforce historically embedded inequalities) by emphasizing real-world 
connections to course content and activities, and by moving away from theoretical abstractions to center the lived-experiences of marginalized groups.

Our approach to global learning emphasizes collaboration, diverse perspectives, and the analysis of complex problems that transcend borders. While the College has always participated in study abroad through direct exchanges and a small set of faculty-led courses every year, the creation of SUMMIT expanded and deepened global learning by connecting the College's general education curriculum to a range of campus-wide, co-curricular programs and by establishing a set of college-wide global learning outcomes. All courses in the global learning curriculum provide opportunities for students to:

1. Identify, explain, and analyze examples of global themes, processes, and systems;

2. Demonstrate knowledge and skills essential for global engagement; and

3. Critically examine the relationship between dominant and marginalized cultures, subcultures, or groups.

All Agnes Scott students begin their global learning in the first year by taking two semesters of a foursemester language requirement. In the Spring of their first year, they also take a semester-long, four-credit global learning course with a one-week faculty-led, cultural immersion experience in March (at no additional cost) ${ }^{2}$ In subsequent semesters, students expand their global learning by taking at least one required interdisciplinary global elective course. The courses that meet this breadth requirement of the general education program (SUMMIT in STEM, Social Sciences, or Arts \& Humanities) must centrally address contact, power, and systems that cross or transcend national borders, and at least one must focus on the critical examination of relationships, interactions and outcomes among dominant and marginalized cultures, subcultures or groups.

Within the same global learning framework, students also still have access to a wide range of subsidized semester-long study abroad experiences at affiliated universities and colleges on most continents and are encouraged to seek out global internship experiences. Students who take the Global Learning Seminar, at least two more global elective courses beyond their global breadth requirement, a language course beyond the intermediate level, and participate in independent study abroad or a global internship can declare a global specialization, awarding them a global learning medallion and a transcript notification.

\section{JOURNEYS: TEACHING DECOLONIZATION THROUGH INTERDISCIPLINARY FACULTY-LED STUDY AWAY}

A course called "Journeys," a semester-long, four-credit class required of all first-year students, forms the cornerstone of Agnes Scott's global learning curriculum. The College usually offers 15 sections each Spring and all sections feature a weeklong, faculty-led global immersion experience in the middle of the semester that carries an additional academic credit. Taught by faculty from across the College, this course forms an entry portal into how liberal arts learning lends itself to the critical analysis of globalization. While faculty bring their respective disciplinary approaches to each section, the overall course structure adapts the above-mentioned college-wide global learning goals for all sections:

- Identify, explain, and analyze global themes, processes, and systems:

- Students will be able to identify and describe through at least two different examples how globalization relates to the particular section topic and analyze its impact on the Journeys destination.

- Critically examine the relationship between dominant and marginalized cultures, subcultures or groups:

- Using specific examples from their Journeys course and the immersion experience, students will be able to compare and contrast the impact global processes have on dominant and marginalized cultures.

- Demonstrate knowledge and skills essential for global engagement:

- Students will be able to evaluate some of the historical, political, economic, scientific, and cultural forces that shape global processes and outline topics for future research and analysis. 
- Students will develop their ability to engage across differences.

- Based on their interactions with and their learning from community members at the Journeys destination students will critically reflect on their own values, ethics, and assumptions.

These learning outcomes strive to engage each student in the process of identifying their own positionalities within dynamic cultural contexts shaped by local-global interactions. Additionally, four common interdisciplinary topical clusters create content cohesion across all sections: identity (self/culture/other); imperialism/colonialism/diaspora; globalization; and the ethics of travel.

Faculty members who teach the core global learning courses go through a rigorous course development sequence rooted in the pedagogical positions of Paolo Freire and the decolonial teaching approaches that have been developed through critical race, postcolonial, poststructuralist, feminist, critical linguistic, and cultural studies. And everything from the array of destinations to which the students travel, the composition of the cohort of faculty leaders and co-leaders, the selection of the third-party site providers, and the placement of students in particular sections is done with a focus on diversity, equity and inclusion.

About a third of the faculty-led global learning courses and the co-curricular global experiences include a service-learning component and a specific connection with community partners. Community partners are identified through third-party providers whose mission aligns with the intentional and critical-inquiry-based approach of ASC's program. The main goal is to organize the logistics of the experience in such a way that the majority of the financial flow benefits the local community. Faculty development workshops emphasize that learning activities on the ground must include actual community perspectives and voices. The Center for Global learning (CGL) usually organizes direct or virtual meetings with representatives of the community and maintains ongoing communication throughout the program. After each program, the CGL solicits specific feedback from the community to hear about concerns or questions.

By design, Journeys avoids a focus on global citizenship, global expertise, and other concepts that have been shown to replicate assumptions about U.S. cultural, economic, and political global hegemony in many study abroad projects (Pipitone 2018, 58; Zemach-Bersin 2009, 305). With the sections addressing topics and sites as varied as "National Identity, Race and Belonging in Cuba," "Music and Identity in the Navajo Nation," "Cultural and Political Crossroads in Central Europe," "Fashion and Globalization in Milan, Italy," "Marine Biology in Croatia" and "Arts and Political Resistance in Chile," the common topics prompt faculty to address how imperialist and colonialist legacies shape the manifestation of globalization regardless of the particular immersion site and disciplinary angle of specific sections (see Graml, et al., 2021)

These common topics also form the basis for the central role of community engagement in the course design and itinerary development. The faculty leaders and the College's faculty-led programs coordinator share with the third-party providers the learning goals and common topics. Given that Journeys courses emphasize learning about globalization's diverging impact on dominant and marginalized groups, faculty leaders and providers collaborate on identifying interlocutors, presenters, and local guides that represent these different voices and perspectives and enable students to engage with the particular, place-based legacies of colonialism. ${ }^{3}$

Recognizing that faculty-led courses often "reproduce hierarchies of power and colonialism, perpetuate views of an exotic cultural 'other,' and privilege tourism over education" (Pipitone 2018, 55), our faculty leaders plan their courses and their travel segments in the context of a year-long, multi-part workshop series that enables them to share teaching practices and assignments. Through the discussion of scenarios and peer-to-peer teaching sessions, faculty expand their pedagogical toolkits to integrate the development of intercultural competencies, practices of intentional reflection, and effective on-site teaching activities that allow students to recognize and critique how today's globalized world relies on the spatialized patterns of colonial/colonialist history. This interdisciplinary faculty development process provides yet another opportunity to rethink study away by prompting faculty to critically reflect on the extent to which their respective disciplines have been complicit in creating and affirming imperialist and colonialist global hierarchies. Just as students begin their global learning by mapping their own identity positions, faculty leaders also begin by questioning implicit norms about learning, teaching, and traveling. 
At the conclusion of a recent faculty workshop, participants engaged in a small group reflection exercise that yielded the following comments about how they thought the project of decolonizing the curriculum is reflected in their courses and others at Agnes Scott ${ }^{4}$ :

- Our attempts to value and respect our students' diverse backgrounds;

- Our willingness to question ourselves and our disciplines;

- Our desire to create culturally and socially relevant learning experiences that will allow our students to better serve and engage with a broad range of communities;

- Our willingness to name systemic racism and oppression, to recognize their role of our institutions and our disciplines in perpetuating inequality, and (one hopes!) to want to do something to dismantle those systems;

- In the way we push back against the dominant rhetoric in the liberal arts that focuses on diversity without naming anti-Blackness.

Beyond the general faculty development for Journeys described above, both faculty and students receive specific preparation to create brave spaces for difficult dialogues to process issues of power and privilege within the context of global learning. We take advantage of workshops and conferences offered externally or bring specialists to campus. The College has even sent faculty and staff on their own global learning immersion experiences to support their development of innovative student-centered pedagogies.

Finally, in an effort to break down binary categories of teachers and students, each Journeys section includes a student peer leader. A group of fifteen upper-class students are selected through an annual, competitive process to support faculty's work. These students participate in a semester-long two-credit internship course where they learn about intercultural pedagogy, group dynamics, and leadership styles. As student leaders they assist the faculty and co-leader throughout the semester and also help the first-year students to establish intentional connections between their learning experiences in this course and their academic plans for the following three years.

The college-wide global learning goals, the common topics with their focus on community engagement, and the intensive course development process provide the foundation for a faculty-led study away experience that disrupts the traditional divide of service-learning courses in the Global South and culture and civilization courses in the Global North. Details from three different Journeys courses (one headed to Latin America and two to European destinations) exemplify this approach.

\section{INTERDISCIPLINARY FACULTY-LED STUDY AWAY: THREE EXAMPLES}

The first example is called "Cultural and Political Crossroads in Central Europe," whose travel segment leads students to Hungary, Slovakia, and Austria. This Journeys course addresses the region's cultural, political, and historical developments, but does so with an emphasis on the manifestations of colonialism and by centering commonly marginalized voices. Students learn about the colonialist and imperialist practices of the Russian, Ottoman, and Habsburg Empire and study global systems by taking a closer look at how these particular manifestations of colonialism were connected to the more widely known and taught British colonialist practices that shaped much of the Global South. By learning about Central Europe as an important point of origin for mid-19th century mass migration to the United States, students also acquire a richer and critical understanding of the formation of diaspora communities in the US. Case studies of the experiences of Jewish, Catholic, and Muslim immigrants from this region allow students a glimpse into the dynamic and shifting conversations about religious, ethnic, and racial identity in the U.S. (see Zahra 2016). Although the course does not visit Switzerland, students read and discuss James Baldwin's experiences in the small Swiss town of Leukerbad, captured in the 1953 essay "Stranger in the Village," in order to engage with different manifestations of systemic global racism and with European constructions of whiteness.

Throughout the semester, students engage with the region's history and culture through the perspectives of Austrian, Czech, Slovakian, and Hungarian authors, filmmakers, and artists. For instance, Czech/Austrian writer Franz Kafka's novel The Penal Colony provides a perspective on the common topic of colonialism and, especially, on the violent practices underpinning colonialist regimes. ${ }^{5}$ A collection of short stories by Roma and Sinti authors, called The Color of Smoke, offers insights into social inequality 
and ongoing colonialist practices within today's European Union (see Lakota 2015). This awareness of imperialist and colonialist structures also shapes the on-site travel experience, from the choice of tour guides to the travel infrastructure.

As Zemach-Bersin (2009) concludes from an analysis of U.S. study abroad websites, "advertisements for international education indulge in the same language as tourism or adventure travel" and prioritize the very consumer attitude that shapes U.S. culture (305). However, while participants in this course do visit some of the well-known tourist sites in cities such as Budapest and Vienna, they do so by intentionally and critically identifying and deconstructing colonialist power structures. In Budapest, students learn to see the city through the eyes of a representative of the Roma community. In Vienna, students stay in a hotel operated by recently arrived refugees and asylum seekers and learn about the city's history and architecture through the eyes of a recently arrived migrant.

Such forms of intentional community engagement try to proactively undermine a colonialist power structure whereby students from a relatively privileged higher education background 'observe' and 'study' local people. Additionally, for faculty-led study tours visiting European destinations, the voices and perspectives of migrants and refugees provide a critical lens through which to perceive the historical and cultural sites.

Another example of a Journeys course, "Fashion and Globalization in Milan, Italy," emphasizes this shift in perspective by foregrounding the role of migrant North African laborers in the global fashion industry and the cultural appropriation of African design by European and U.S. American fashion companies. ${ }^{6}$ A feature-length documentary directed by Andrew Morgan focuses students' attention on "fast fashion," and the environmental, social and psychological effects of the garment industry and global capitalism (see Morgan 2015 "The True Cost"). Such intentional course design foregrounds what historian Dipesh Chakrabarty (2000) described as the crucial post-colonialist practice of "provincializing Europe," the critical task of exploring how [European] thought -- which is now everybody's heritage and which affects us all--may be renewed from and for the margins" (16). These margins can be situated in the Global South, as demonstrated by Journeys courses such as "Art and Political Resistance in Chile," where students identify and engage with forms of political agency expressed through combinations of indigenous and international art forms and artistic collaboration. But, as shown in the discussion of the European-focused courses, they also need to be identified in the global North.

Agnes Scott's global learning curriculum explicitly acknowledges that the U.S. is part of the global dynamics under examination and that domestic destinations such as the Navajo Nation, New Orleans, Puerto Rico, or New York allow for an examination of the legacies of colonialism closer to home, while also providing options for our DACA or other first year students who cannot travel outside the U.S.

The final course example, "Race and Citizenship Across the Americas," focuses on two American contexts -- the U.S. and Panama -- intentionally linking them to urge students to think about race and capitalism globally. The course is divided into four parts: Part I of the semester is focused on examining the concept of citizenship from an interdisciplinary perspective, especially how it is influenced by race, class, gender and national culture. And in Part II of this class, students consider how these social constructions have intersected and influenced each other in particular historical moments. By traveling to sites in Panama City, Colon and Costa Arriba students move beyond the dominant historical narratives around national identity to explore examples of BIPOC agency and meaning making related to West Indian immigration and labor, black resistance to Spanish colonialism (the cimarrons of Panama), environmental activism, and economic development among indigenous groups. The students return to our Agnes Scott classroom with the beginnings of intercultural perspectives on how inequalities of race and citizenship in the U.S. and Panama are connected.

Prior to departure, an early class session includes a viewing of Chimamanda Ngozi Adichie's (2009) TEDTalk, "The Danger of a Single Story," followed by small group discussions. This video, which is popular among global learning scholars and DEI practitioners as an entry point to conversations around implicit bias, argues that stereotypes come from "single stories" about marginalized groups. Typically, students begin the semester sharing accounts about times they've been misread and stereotyped, but they avoid any mention of oppression, inequality, power, and privilege. In other words, they talk about race 
without talking about race. But by the time students discuss course materials such as Sarah Manyika's (2003) autoethnographic essay, "Oyinbo," they are able to draw on an array of pre-departure and on-site experiences to question color-blind assumptions and ahistorical perspectives on social problems in society. They begin to see connections between global anti-blackness and the systematic oppression of certain groups in different societies. Moreover, by discussing concepts of "self" and "other" as dynamic and as culturally constructed, students learn to identify and trace tangible manifestations of global patterns in human interactions, a process that contributes significantly to the breakdown of simplistic categorizations of "us" and "them" ("here" and "there") that permeate study abroad experiences (Pipitone 2018, 69).

Instead of preparing students solely for encountering "a place," in their Journeys classes students reflect on their own construction of intimate and public notions of place and begin to identify how these constructions align with or differ from similar processes in their destination communities. Intentional reflection activities before, during, and after the global immersion travel week enable students to develop and practice various approaches to a decolonized global learning experience that disrupts a Western travel habitus. Before traveling, students learn about the history and culture of the section-specific global learning destinations and how the legacy of colonialism and contemporary globalization affects its various communities in disparate ways. Students across all sections engage with cultural texts such as Jamaica Kincaid (1988) A Small Place which address the role of identity, traveling, and colonialism. Instead of simply preparing for a critical investigation of the colonialist legacy on site, these readings prompt substantive reflections and discussions about students' own roles in globalized power structures.

Notably, destructive resource extraction and environmental degradation are legacies of colonialist practices that continue in today's globalized world and demand a particularly urgent response given the rapidly emerging climate catastrophe. Faculty leaders address these topics in intentional ways through course design as well as choice of destination and collaborators on the ground. The common topic of "Ethics of Travel" prompts students to consider their own lifestyle choices and to acknowledge the responsibility that comes with the opportunity to combine traveling and learning. Regardless of their own particular socioeconomic and cultural background, students' participation in the global immersion experience generates a carbon footprint that exceeds the annual emissions of a person in less developed countries. Leading up to the Journeys course, students can participate in a series of competitive sustainability-related education activities on Agnes Scott's campus in which they learn to calculate and compare the carbon footprint generated by their study abroad travel with global emissions profiles. Students also design ways of mitigating the environmental impact of their travel through lifestyle adaptations such as dietary changes and using public transportation.

Upon return, students meet with peers from other Journeys sections and discuss how they engaged with the common topics in the various locations. For instance, students who traveled to Eastern Europe, to Cuba, and to Ghana will thus discuss the (post-)colonialist aspects of globalization from the perspective of the colonized and the colonizing, metropolitan context. For first-year students, these common reflections across sections underscore that their global immersion is only the initial step in a sustained practice of critical inquiry into global power structures. By sharing how colonial patterns manifested themselves in the global patterns and systems they encountered in their various destinations, students also gain an awareness that the meaning of place in the context of the global must be seen not as a fixed and bounded geographical entity but, in the words of feminist geographer Doreen Massey (1994), as "particular moments in [...] intersecting social relations, nets of which have over time been constructed, laid down, interacted with one another, decayed and renewed" (120). Such an understanding enables students to see the global not as antithetical to the local but as a crucial matrix for studying and learning about themselves and their more immediate environment. In this way the course provides students with the critical scaffolding to learn from and question the differences they encounter and prevents students from reaffirming cultural stereotyping as well as essentialist notions of place.

In short, breaking down calcified notions of intercultural encounters as leaving one's "own" place and entering an "other" place enables students to identify and discuss more complex notions of global identity patterns and facilitates more meaningful engagement. Because all of the sections of this required course use community engagement to try to proactively undermine structures and systems of inequity, we suggest that 
our efforts to build better relationships between students and local hosts, and to develop strategic partnerships with providers that support ethical work with diverse communities represents a unique approach that interrupts power dynamics associated with race and nationality that are normalized in many faculty-led programs. Moreover, by frontloading the global experience, students have three more years in which they can build and curate their liberal arts majors and minors based on the questions the first-year global learning experience helped them to ask.

\section{CULTIVATING GLOBAL LEARNING BEYOND THE CLASSROOM}

In the co-curricular arena, the College takes advantage of the complex landscape of the greater Atlanta region for students to explore some of the ongoing local impacts of what Cedric Robinson (1983) described as racial capitalism. For example, on the topic of immigration alone, students engage in domestic servicelearning projects with Global Growers, a local organization connecting the agricultural talent of the local refugee communities to opportunities in sustainable agriculture. Students also worked with El Refugio, an organization supporting ICE detainees, and designed an alternative spring break experience on "The Need for Fair Food: Migrant Farm Workers and Human Trafficking" that included studying pre- and postcolonial Florida history. Opportunities for advocacy such as a training workshop on Latinx Social Activism in Georgia and honoring "I Stand with Immigrants Day" allow students to put their learning into action. In addition, guest speakers such as Richard Blanco, who read from his memoir The Prince of Los Cocuyos, and Isabel Wilkerson, who discussed her book The Warmth of Other Suns, connect students' learning with relevant public debates. Films, panels, and opportunities for political advocacy opportunities broaden students' understanding of these complex topics.

Notably, students begin their global learning experience right after new student orientation in an intensive 72-hour program called "Legacy." The retreat includes an afternoon on "leading in a global society" where students, in small groups, take part in activities on identity, diversity, power and privilege, as well as what it means to live in an inclusive community of respect (focused on understanding microaggressions and civil discourse). After that they tour the Center for Civil and Human Rights together to learn about leadership in the Civil Rights movement in the context of Atlanta.

As a college for women and other marginalized genders, Agnes Scott's approach to both curricular and co-curricular liberal arts learning strives to take into account the intersectional impact of race, gender, class and sexual identity on local and global issues. For example, there are numerous student-led panels offered prior to departure on their Journeys on topics like "Black Students Perspectives on Study Abroad," or similar panels designed for Muslim students or queer students, and these have contributed to sending students for semesters abroad in proportionate diversity. The College spoke up about the impact of the travel ban on vulnerable populations, and we always attend to the specific global learning needs and challenges of undocumented students.

\section{CONCLUSION}

In this paper, we have highlighted the importance of:

- Connecting global learning with an institution's mission;

- Incentivizing, developing, and maintaining strong faculty support;

- Developing strategic partnerships with third-party providers that support ethical work with communities in destinations; and

- Fostering meaningful cross-campus collaboration between academic affairs, student affairs, and diversity, equity and inclusion divisions to increase access to global learning for traditionally underrepresented groups.

Agnes Scott is learning many lessons about the ongoing, never-ending project of cultivating social justice through international education which could be transferable outside of the College's current global learning experience. 
First, we argue that it is critical to define key terms (e.g. what you mean by global) and outcomes at the outset in a way that takes social justice into account, and to keep those goals in mind as the curriculum is developed. Secondly, new initiatives do not need to be perfected in the abstract before launch, but can be refined through iterative thinking and adaptive systems: assess-analyze-change-repeat. In that process, student experiences must be kept central and all perspectives heard at each stage. We've also learned that faculty need to drive curricular changes, but can partner with administrators, engage with community partners and break down silos. Every institution has its own culture and history, and can build on past successes to avoid past pitfalls. While it undoubtedly will look different everywhere, our experience suggests that a liberal arts education is uniquely positioned to build the capacity for meaningful intercultural engagements that are more valuable now than ever before.

\section{ACKNOWLEDGEMENTS}

The authors wish to thank Elaine Meyer-Lee and the faculty and staff at Agnes Scott College who have shared in the work of developing SUMMIT and the Global Learning curriculum.

\section{ENDNOTES}

1 This paper is based on a workshop prepared for the 6th Annual Global Service Learning Summit, Clemson University, SC - November 2019.

2 The fact that this global immersion experience is included in the cost of tuition itself disrupts socioeconomic privilege hierarchies by including all students regardless of financial need.

3 For instance, any cursory review of publicly available faculty-led course titles offered by U.S. universities and private study abroad providers reveals an ongoing North - South divide: courses with destinations in the Global North emphasize the achievements of Western civilization and feature visits to centers of political and economic power as well as dominant cultural and historical sites and attractions; while courses visiting destinations in the Global South tend to foreground service learning and community involvement where students can observe the problematic legacy of colonization.

4 Participants were asked to generate bullet points to complete the sentence: "At Agnes Scott, our efforts to decolonize the curriculum are reflected in ..."

5 For a reading of Kafka's seminal short story in the context of postcolonial studies see Goetschel, W. (1981) Franz Kafka's 'In Der Strafkolonie.' The Germanic Review: Literature, Culture, Theory, 90(2), 81-86.

6 See "European Control of African Textile Industry | ANWO." Accessed December 20, 2019. https://anwouhuru.org/european-control-of-african-textile-industry/.

\section{REFERENCES}

Adichie, C.N. (2009). The Danger of a Single Story. TED Global. Retrieved from https://www.ted.com/talks/chimamanda_ngozi_adichie_the_danger_of_a_single_story

Baldwin, J. (1953, October). Stranger in the Village. Harper's Magazine. Retrieved from https://harpers.org/archive/1953/10/stranger-in-the-village/

Blanco, R. (2014). The Prince of Los Cocuyos: A Miami Childhood. Harper Collins.

Chakrabarty, D. (2000). Provincializing Europe: Postcolonial Thought and Historical Difference. Princeton, N.J: Princeton University Press.

Goetschel, W. (2015). Franz Kafka's 'In Der Strafkolonie.' The Germanic Review: Literature, Culture, Theory, 90(2), 81-86. https://doi.org/10.1080/00168890.2015.1038495

Graml, G., Meyer-Lee, E., \& Peifer, J.S. (2021). Decolonizing Global Learning and Internationalization: A Human-Scale Case Study of Innovation. In People-Centered Approaches Toward the Internationalization of Higher Education. IGI Global. Retrieved from https://doi.org/10.4018/978-1-7998-3796-1.ch007

Kafka, F. (2017). In the Penal Colony. Sheba Blake Publishing.

Kincaid, J. [1988] (2000). A Small Place. New York: Macmillan. 
Lakatos, M. (Ed.). (2015). The Color of Smoke. Translated by Ann Major. New Europe Books.

Manyika, S. (2003). Oyinbo. In P.C. Hintzen \& J.M. Rahier (Eds.), Problematizing Blackness: SelfEthnographies by Black Immigrants to the United States (pp. 65-83). New York: Routledge.

Massey, D.B. (1994). Space, Place, and Gender. University of Minnesota Press.

Mitchell, T.D., Donahue, D.M., \& Young-Law, C. (2012). Service Learning as a Pedagogy of Whiteness. Equity \& Excellence in Education, (4), 612-29. https://doi.org/10.1080/10665684.2012.715534

Morgan, A. (2015). The True Cost. Retrieved from https://truecostmovie.com

Pipitone, J.M. (2018). Place as Pedagogy: Toward Study Abroad for Social Change. Journal of Experiential Education, 4l(1), 54-74. https://doi.org/10.1177/1053825917751509

Robinson, C. [1983] (2000). Black Marxism: The Making of the Black Radical Tradition. Chapel Hill: University of North Carolina Press.

Wilkerson, I. (2010). The Warmth of Other Suns: The Epic Story of America's Great Migration. Knopf Doubleday Publishing Group.

Zahra, T. (2016). The Great Departure: Mass Migration from Eastern Europe and the Making of the Free World. New York: W.W. Norton.

Zemach-Bersin, T. (2009). Study Abroad Marketing and the Privatization of Global Citizenship. In R. Lewi (Ed.), The Handbook of Practice and Research in Study Abroad: Higher Education and the Quest for Global Citizenship (pp. 303-320). New York: Routledge. 